\title{
Orthopedic Problems in Family Caregivers of Palliative Care Patients
}

\author{
Esra Pehlivan ${ }^{1}\left({ }^{\circ}\right.$, Arif Balci $^{2}$ \\ ${ }^{1}$ University of Health Sciences, Faculty of Health Science, Department of Physiotherapy and Rehabilitation \\ ${ }^{2}$ University of Health Sciences, Yedikule Chest Diseases and Thoracic Surgery Training and Research Hospital, Pulmonary Rehabilitation Department \\ Correspondence Author: Esra Pehlivan \\ E-mail: esra.pehlivan@sbu.edu.tr \\ Received: $25.02 .2019 \quad$ Accepted: 01.07 .2019
}

\begin{abstract}
Objective: The studies on caregivers focus more on their psychological impact. The caregivers' orthopedic problems are not taken into consideration. We aimed to determine the orthopedic problems of the patient family caregivers and to examine the relationship with burden of care.

Methods: Caregivers of palliative care who look after the patient recieving palliative care at least two months were included in the study. The outcome measurements: Oswestry neck pain questionnaire,arm shoulder hand disability questionnaire (DASH), Western Ontario and McMaster osteoarthritis index (WOMAC), Short Form 36 (SF-36), International Physical Activity Questionnaire (IPAQ), Zarit Burden Interview (ZBI) and BECK depression inventory (BDI).

Results: A cross-sectional study was carried our with fourty-two caregivers who averaged 50 years, were mostly female (81\%), married (76\%) and housewife (59\%). Mean DASH score was 18.82, while Oswestry score was 22.18. According to the IPAQ total score, the cases were in the physically active category (10145 MET). In all SF36 subgroup, there was a statistically insignificant decrease compared to normative values ( $p>0,05)$. Total burden score was 38,64 . The ZBI correlated with DASH ( $r=0,479)$, WOMAC $(r=0,453)$, Oswestry $(r=0,645)$ many SF36 subgroups $(p<0,05)$ and BDI $(\mathrm{p}<0,001)$.

Conclusion: There are some orthopedic problems besides psychological problems related to the burden of family caregivers. Strategies should be developed to provide education and support for the development of methods for the prevention and treatment of orthopedic problems affecting the quality of life of family caregivers.
\end{abstract}

Keywords: Burden of care, quality of life, physical activity

\section{INTRODUCTION}

The expectation of the family members for the patient in the terminal period is extending the life span or a peaceful death (1). The role of family members responsible for patient care in overcoming and challenging is important in this difficult period (2).

The purpose of palliative care is to meet the physical and psychological needs of the patient in the recent period, as well as the support of the patient relatives in this process (3). The guidelines have emphasized the importance of acknowledging the patients' and family caregivers' needs and wishes to guide decision-making and care planning (4).

Patient and caregivers in the palliative care have little participation in studies (5). Therefore, there is limited data available about this issue (6). The studies carried out are more about psychological influences of caregivers and strategies for coping with the present situation (7-9). In our literature search, we found only the studies related to orthopedic problems of family caregivers who have children with disabilities (10). The patient population of our study is family caregivers who are obliged to take care of relatives who have lung cancer or severe lung diaseses and are admitted to a palliative care clinic. The patients are dependent on the bed and need to make compulsive physical exertion by their relatives during patient care. We have not found a similar study that has been related to this topic and has been performed before in this population.

The aims of our study were to determine the orthopedic problems of the patient caregivers who take care of the patient recieving palliative care and to examine the effect of this amount on the patient care burden.

There are two main hypothesis of this study:

1) The orthopedic problems may occur in caregivers in palliative care.

2) The orthopedic problems in caregivers affects their quality of life.

\section{METHODS}

\subsection{Study design}

The study was a cross-sectional, observational study. 


\subsection{Setting-participant}

Between May 2018 and July 2018, 42 family caregivers of palliative care patients who took primary care for at least two months were included in the study. The caregivers taking the patient care less than two months shorter were excluded from the study. Ethics approval was obtained from Local University Ethics Committee (Protocol Number: 1271), and the study was conducted in accordance with the Helsinki Declaration. Written informed consent was obtained from each human subjects.

\subsection{Variables}

The general clinical and demographic characteristics of the patients were recorded. Oswestry neck pain questionnaire, arm shoulder hand disability questionnaire (DASH), Western Ontario and McMaster osteoarthritis index (WOMAC) were used to determine the orthopedic problems of caregivers. Short Form 36 (SF-36) was used for determining the quality of life, International Physical Activity Questionnaire (IPAQ) for physical activity levels and Zarit Burden Interview (ZBI) for patient care. Questionnaires were asked caregivers by physiotherapist.

\subsubsection{Questionnaires}

\subsubsection{Disabilities of Arm, Shoulder and Hand Questionaire (DASH)}

The DASH, consisting of 30 questions and evaluates the functional status of the upper extremity subjectively based on the Likert scale. According to the questionnaire, a score of $0-100$ is obtained from each section $(0=$ no disability, $100=$ maximum disability) (11).

\subsubsection{Western Ontario ve McMaster Osteoartrit Index (WOMAC)}

The WOMAC consist of 24 items divided into 3 subscales (pain, stiffness, physical function). On the Likert Scale version, the scores are summed for items in each subscale, with possible ranges as follows: pain $=0-20$, stiffness $=0-8$, physical function=0-68 (12).

\subsubsection{Oswestry Neck Disability Index}

It is a modification of the disability index of the Oswestry low back pain (13). The maximum score is 50 . A score of 0 to $8 \%$ indicates no disability, while scores of $10-28 \%, 30-48 \%$, $50-68 \%$, and $70-100 \%$ represent mild, moderate, severe disability and completely disabled, respectively (13).

\subsubsection{International Physical Activity Questionaire (IPAQ)}

The 31-item long form and the 9-item short form assess time spent on different activities. Participants were classified into three PA categories: those getting less than $600 \mathrm{MET}-\mathrm{min}$./wk. were considered to be insufficiently active (Low PA); those with between 600 and 3000 MET-min./wk. were considered to be sufficiently active (World Health Organization, 2010) and they were classified as Moderate PA; those reporting more than 3000 MET-min./wk. were classified as High PA (14).

\subsubsection{Zarit Burden Interview (ZBI)}

The $\mathrm{ZBI}$ is a widely used tool to describe caregiver burden. Each item is scored from 0 to 4 , where $0=$ never, 1 = rarely, 2 = sometimes, 3 = quite frequently, and 4 = nearly always. In the questionnaire, patients' caregiving burden is categorized as mild to moderate (21-40), moderate to severe (41-60) and severe burden (61-88).

\subsubsection{Short Form 36 (SF36)}

The SF-36 is a short form questionnaire with 36 items that measure eight health related quality of life domains: physical functioning (PF), social functioning (SF), role limitation due to physical problems (RP), role limitation due to emotional problems (RE), mental health (MH), energy and vitality (VT), bodily pain (BP), and general perception of health (GH), Physical Component Score (PCS) and Mental Component Score (MCS) (15). In the study, SF36 scores were compared with normative values of Turkish population (16).

\subsubsection{BECK Depression Inventory (BDI)}

Total score ranges from 0 to 63 , with higher scores indicating higher levels of depressive symptoms (17).

Bias: The surveys were conducted by the same physiotherapist in order to avoid any potential biases and the statistical analysis was performed by a different physiotherapist.

\subsection{Statistical analysis}

Statistical Package for Social Science (SPSS) version 15 for windows (SPSS Inc. Chicago, IL, USA) was used for statistical analysis. We used the Shapiro-Wilk test to test the normal distribution of the variables. The descriptive analyses of the qualitative variables were presented in absolute and relative frequencies. Continuous variables with not normal distribution were presented as median and mimimummaximum. Pearson correlation test were used to correlate the variables in appropriately indicated points. For all the statistics, $p<0.05$ was considered significant.

\section{RESULTS}

\subsection{Participants}

\subsubsection{Patient}

The mean age of the patients was 66 , and the diagnostic distributions were predominantly lung cancer $(23 \%)$. The vast majority of patients complained of severe dyspnea (\%61) (Table1). 
Table 1. Demographic characteristics and diagnostic distributions of the patients.

\begin{tabular}{|l|c|}
\hline Variable & N (\%) or median (min-max) \\
\hline Demographic characteristics & $34 / 8(81 / 19)$ \\
Gender (female/male), $n(\%)$ & $66,95(23-92)$ \\
Age (year) & \\
\hline Anthropometry & $26,53(15,55-39,06)$ \\
BMI (kg/m $\left.{ }^{2}\right)$ & \\
\hline mMRC (0-4) & $2(4,8)$ \\
0 & $4(9,5)$ \\
1 & $1(2,4)$ \\
2 & $9(21,4)$ \\
3 & $26(61,9)$ \\
4 & \\
\hline Diagnosis, $n(\%)$ & $23(54,8)$ \\
Lung cancer & $13(31)$ \\
COPD & $3(7,1)$ \\
Bronchiectasis & $2(4,8)$ \\
Pneumonia & $1(2,4)$ \\
Prostat cancer & \\
\hline
\end{tabular}

BMI: Body Mass Index, COPD: Chronic Obstructive Lung Disease, mMRC Modified Medical Research Council Dyspnea Scale.

Table 2. Demographic characteristics of the family caregivers.

\begin{tabular}{|c|c|}
\hline Variable & $\mathrm{N}(\%)$ or median (min-max) \\
\hline $\begin{array}{l}\text { Demographic characteristics } \\
\text { Gender (male/female), } n(\%) \\
\text { Age (year) }\end{array}$ & $\begin{array}{l}8 / 34(19 / 81) \\
50,57(20-74)\end{array}$ \\
\hline $\begin{array}{l}\text { Anthropometry } \\
\mathrm{BMI}\left(\mathrm{kg} / \mathrm{m}^{2)}\right.\end{array}$ & $26,53(15-39)$ \\
\hline Length of education (year) & $7,97(5-16)$ \\
\hline $\begin{array}{l}\text { Work status }(n, \%) \\
\text { Housewife } \\
\text { Officer } \\
\text { Worker } \\
\text { Bank officer } \\
\text { Childminder } \\
\text { Electrician } \\
\text { Real estate agent } \\
\text { Public relations specialist } \\
\text { Operater } \\
\text { Designer } \\
\text { Accountant }\end{array}$ & $\begin{array}{c}25(59,5) \\
5(11,9) \\
1(2,4) \\
1(2,4) \\
1(2,4) \\
1(2,4) \\
1(2,4) \\
1(2,4) \\
4(9,5) \\
1(2,4) \\
1(2,4) \\
\end{array}$ \\
\hline Average working year & $13,75(3-30)$ \\
\hline $\begin{array}{l}\text { Marital status } \\
\text { Maried/single (n, \%) }\end{array}$ & $32 / 10(76 / 24)$ \\
\hline Children & $2(0-9)$ \\
\hline $\begin{array}{l}\text { Comorbidities ( } n, \%) \\
\text { Hypertension } \\
\text { Diabetes Mellitus } \\
\text { Hypertension+ Diabetes Mellitus } \\
\text { Asthma } \\
\text { Bronchitis } \\
\text { Tuberculosis } \\
\text { Gastrointestinal tumor operation } \\
\text { Lumbal disc herniation } \\
\text { Knee ACL Rupture operation }\end{array}$ & $\begin{array}{l}5(11,9) \\
2(4,8) \\
2(4,8) \\
1(2,4) \\
1(2,4) \\
1(2,4) \\
1(2,4) \\
1(2,4) \\
1(2,4)\end{array}$ \\
\hline
\end{tabular}

BMl: Body Mass Index, ACL:Anterior Curciat Ligamet.

\subsubsection{Caregivers}

The caregivers ( $n=42)$ averaged 50 years, were mostly female $(81 \%)$, married $(76 \%)$ and housewife $(59 \%)$ were included the study. Five caregiver had hypertension (11\%), 2 had diabetes mellitus $(4.8 \%)$, and 2 had hypertension plus diabetes mellitus in the additional disease profiles. There were 2 caregivers with orthopedic disease (lumbar disc hernia, knee anterior curciat ligament rupture operation) (Table 2).

\subsection{Outcome data}

The DASH function / symptom score was 18.82. Caregivers had minimal arm-shoulder-hand disability. The maximum total score for WOMAC osteoarthritis index was 100, while the total score for the cases was 18.95. The WOMAC subscale scores were given in Table 3.

Table 3. The orthopedic problems, physical activity levels and burden of care of caregivers.

\begin{tabular}{|l|l|l|}
\hline Variables & $\begin{array}{l}\text { Median } \\
\text { (min-max) or n(\%)* }\end{array}$ & Possible Range \\
\hline DASH-F/S & $18,82(0-49,2)$ & $0-100$ \\
\hline WOMAC & $18,99(0-77)$ & $0-100$ \\
Total & $4,07(0-12)$ & $0-20$ \\
Pain & $1,58(0-6)$ & $0-8$ \\
Stifness & $13,02(0-66)$ & $0-68$ \\
Physical Function & & \\
\hline Oswestry NDI & $22,18(0-100)$ & $0-100$ \\
Total score & $15(\% 35,7)$ & 0 to $8 \%$ no disability \\
No disability & $15(\% 35,7)$ & $10-28 \%$, mild \\
Mild disability & $8(\% 19)$ & $30-48 \%$, modarete \\
Moderate disability & $3(\% 7,1)$ & $50-68 \%$, severe \\
Severe disability & $1(\% 2,4)$ & $70-100 \%$, completely \\
Completely disabled & & disabled \\
\hline IPAQ & $10145(0-97020)$ & Inactive <600MET \\
Total PA (MET-min/week) & $312,85(0-1080)$ & Moderate 600- \\
Walking MET(min/week) & $192,38(0-3920)$ & $3000 M E T$ \\
Moderate MET(min/week) & $73,90(0-1344)$ & Active >3000MET \\
Vigorious MET(min/week) & & \\
\hline ZBI & $38,64(17-69)$ & $0-88$ \\
\hline & & \\
BDI & $13,57(0-61)$ & $0-9$ normal \\
& & $10-18$ mild \\
& & $19-29$ modarete \\
& & $30-63$ severe \\
\hline
\end{tabular}

DASH-F/S: Disabilities of Arm, Shoulder and Hand Questionaire-Function/ Semptom score, WOMAC: Western Ontario ve MCMaster Osteoarthritis Index, Oswestry NDI: Oswestry Neck Disability Index, IPAQ: International Physical Activity Questionaire, PA: Physical Activity, 2BI: Zarit Burden Interview scale, BDI: Beck depression inventory. *Values are expressed as median (minimum-maximum) or number (percentage).

There was a small amount of complaints related to osteoarthritis in the caregivers. Oswestry neck pain index total score was 22. A total of "moderate" neck pain was detected in the caregivers. Fifteen of the relatives had no disability $(35,7 \%), 15(35,7 \%)$ had mild disability, $8(19 \%)$ moderate and $1(2.4 \%)$ severe disability (Table3). The IPAQ 
total score was 10145 MET (min/week) and cases were in the physically active category (total score $>3000$ MET means active). Fifteen (35\%) caregivers were sufficently active, 12 $(28 \%)$ were moderate active, $3(7 \%)$ were high level active (Table 3). The Zarit burden of care score was calculated as 38.64. This value corresponds to mild to moderate burden (Table 3). The BECK depression score was calculated 13,57. This value corresponds to mild depression level (Table 3 ).

In all SF36 subgroup categories, there was a statistically insignificant decrease compared to normative values in Turkey ( $>>0,05)$ (Table 4). Although the total physical and mental scores were not statistically significant (respectively; $p=0.6, p=0.8$ ) but they were numerically higher than the Turkey average scores.

In the correlations analysis showed Zarit burden of caregivers score was correlated with DASH $(r=0.479, p=0.002)$, WOMAC ( $r=0,453, p=0,003)$, Oswestry $(r=0,645, p<0,001)$, many SF36 subgroup scores (pain, general health, vitality, social function, emotional role; $p<0,05)$ and BECK depression score $(r=0,514, p<0,001)$ (Table 5).
Table 4. Statistical differences of scores between normative data and scale scores of family caregivers.

\begin{tabular}{|l|c|c|l|l|}
\hline Variables & $\begin{array}{c}\text { Median (min- } \\
\text { max) }\end{array}$ & $\begin{array}{c}\text { Norm-based } \\
\text { scores } \\
\text { Median* }\end{array}$ & $\mathbf{z}$ & $\mathbf{p}$ \\
\hline SF36 & & & & \\
PF & $80,00(25-100)$ & 100 & $-1,463$ & 0,144 \\
RP & $25,00(0-50)$ & 100 & $-1,773$ & 0,076 \\
BP & $56,25(10-100)$ & 100 & $-1,457$ & 0,145 \\
GH & $50,00(5-95)$ & 72 & $-1,132$ & 0,258 \\
VT & $50,00(0-95)$ & 70 & $-0,808$ & 0,419 \\
SF & $62,50(0-100)$ & 100 & $-1,421$ & 0,155 \\
RE & $16,66(0-50)$ & 100 & $-1,802$ & 0,072 \\
MH & $58,00(0-80)$ & 76 & $-1,421$ & 0,155 \\
PCS & $53,12(23-86)$ & 54 & $-0,081$ & 0,936 \\
MCS & $43,37(3-80)$ & 52 & $-0,484$ & 0,629 \\
\hline
\end{tabular}

SF36: Short Form 36, PF: Physical Function, RP: Role-Physical, BP: Bodily Pain, GH: General Health, VT: Vitality, SF: Social Function, RE: Role Emotional, MH: Mental Health, PCS: Physical Component Score; MCS: Mental Component Score. * SF36 normal values of Turkish population were taken.

Table 5. Pearson correlations between orthopedic problems and burden of caregivers.

\begin{tabular}{|c|c|c|c|c|c|c|c|c|c|c|c|c|c|}
\hline & DASH & WOMAC & Oswestry & $\begin{array}{l}\text { IPAQ } \\
\text { Total }\end{array}$ & $\begin{array}{l}\text { SF36 } \\
\text { PF }\end{array}$ & $\begin{array}{l}\text { SF36 } \\
\text { RP }\end{array}$ & $\begin{array}{l}\text { SF36 } \\
\text { BP }\end{array}$ & $\begin{array}{l}\text { SF36 } \\
\text { GH }\end{array}$ & $\begin{array}{l}\text { SF36 } \\
V T\end{array}$ & $\begin{array}{l}\text { SF36 } \\
\text { SF }\end{array}$ & $\begin{array}{l}\text { SF36 } \\
\text { RE }\end{array}$ & $\begin{array}{l}\text { SF36 } \\
\text { MH }\end{array}$ & BDI \\
\hline $\begin{array}{l}\text { ZBI } \\
r \\
P\end{array}$ & $\begin{array}{l}, 479^{*} \\
, 002\end{array}$ & $\begin{array}{l}, 453^{*} \\
, 003\end{array}$ & $\begin{array}{l}, 645^{*} \\
, 000\end{array}$ & $\begin{array}{l}-, 159 \\
, 314\end{array}$ & $\begin{array}{l}-, 060 \\
, 708\end{array}$ & $\begin{array}{l}-, 270 \\
, 083\end{array}$ & $\begin{array}{l}-, 486^{*} \\
, 001\end{array}$ & $\begin{array}{l}-, 408^{*} \\
, 007\end{array}$ & $\begin{array}{l}-, 365^{*} \\
, 017\end{array}$ & $\begin{array}{l}-, 467^{*} \\
, 002\end{array}$ & $\begin{array}{l}-, 589 * \\
, 000\end{array}$ & $\begin{array}{l}-, 300 \\
, 054\end{array}$ & $\begin{array}{l}, 514^{* *} \\
0,000\end{array}$ \\
\hline
\end{tabular}

ZBI: Zarit Burden Interview. DASH: Disabilities of Arm, Shoulder and Hand Questionaire-Function/Semptom score, WOMAC: Western Ontario ve McMaster Osteoarthritis Index, Oswestry: Oswestry Neck Disability Index, IPAQ: International Physical Activity Questionaire, SF36: Short Form 36, PF: Physical Function, RP: Role-Physical, BP: Bodily Pain, GH: General Health, VT. Vitality, SF: Social Function, RE: Role Emotional, MH: Mental Health; BDI: Beck depression inventory. *Correlation is significant, $p<0,05$ (two-tailed).

\section{DISCUSSION}

Our study was a cross-sectional and observational study. It was found that family caregivers who are obliged to take care of the their patients in the palliative care clinic are mostly middle-aged, female subjects. The caregivers' complaints of shoulder and osteoarthritis were minimal and neck failure was moderate. The cases were physically active individuals. Their quality of life was similar to that of Turkey normative datas. Patient burden loads were in the mild to moderate category. It has been determined that the amount of burden of care loads and orthopedic problems and quality of life are related.

In a study of the caregivers of patients with Chronic Obstructive Pulmonary Disease (COPD), the majority of caregivers were female $(85.3 \%)$, married $(59 \%)$ and had low levels of income and schooling (18). In another patient group, primary caregivers of juvenile idiopathic arthritis patients were the mostly women $(91.4 \%)$, married $(76.6 \%)$, mothers $(92.2 \%)$ and their average age was $37.2+/-8.8$ years (19). In our study, it was determined that the majority of family caregivers were female, married, housewife in a similar way to the literature. At the same time, in our study, the physical activity profiles of caregivers were examined and it was observed that the individuals were physically active individuals.

Studies on caregivers focus more on their psychological impact. A study of caregivers on cerebral palsy reported that the physical and psychological health of caregivers was related to the disability rates of their children (20). Almost all of the studies related to caregivers with orthopedic problems are related to caregivers of disabled child (21). In a cross sectional study, 90 female family members who took care of their disabled children in pediatric clinic reported that their physical functioning decreased in proportion to the physical disability rates of the children and this increased pain complaints (10). In this population, the basis of the orthopedic problems of family members lies in the harm of the caregiver during the transfer of disabled child. Among studies, it was found that the prevelence of low back pain was higher in caregivers of children needing assistance with transfers (22). In our study, orthopedic problems of family caregivers who were obliged to take care of chronic respiratory patients in palliative care clinic were examined. Minimal and moderate orthopedic problems identified in 
the cases of shoulder, neck and general osteoarthritis. We also accept that the symptoms on the measures used may well arise from psychological distress. But it is emphasized that primary caregivers of our study may be affected not only psychologically but at the same time orthopedically, and that the individuals should also support from this perspective.

The quality of life of individuals who undertake long-term patient care is adversely affected. In a study involving 170 multiple sclerosis patients, the quality of caregivers was examined. It has been shown that if the caregivers have a low education level and the illness process is long, the caregiver needs further support (23). In a study of the factors affecting the quality of life of COPD relatives, researchers found that mean caregiver physical and mental total scores were $45.9+/-10$ and $46+/-12$, while the mean total burden score was $1.79+/-0.6(18)$. In the same study, it is emphasized the importance of caregiver mental scores and patient physical total scores to be important predictors of burden (18). In our study, the quality of life of caregivers was examined using the SF36 quality of life questionnaire, and the data obtained were compared with the norms of our country obtained from a previous study (16). The quality of life scores in all subcategories of caregivers although numerically lower, were statistically similar. This may be related to how much patient care is continued.

The burden of care defined by the caregivers depends on many factors and the burden load is related to the quality of life. In a cross-sectional study about dialysis patients caregivers, SF36 total physical and mental subscores were slightly lower and total physical score was reported to be associated with younger age and higher ZBI score. At the same time, it was emphasized that the decline in quality of life is also related to the high burden of care (24). We also found that the burden of care in our study was mild to moderate with the ZBI. In the analysis of correlation, we found that the burden of care is related to orthopedic problems, quality of life and depression level. The study was a cross-sectional study. In most of the parameters, there is no normative values of Turkish society and no comparison can be made. There was no control group included in the study design.

\section{CONCLUSION}

A number of orthopedic problems can be seen in the family caregivers of the palliative care patients in relation to their caregiver burden. It is necessary to develop strategies to provide education and support for the development of methods for the prevention and treatment of orthopedic problems affecting the quality of life of family care givers.

Acknowledgements: Authors thank to the subjects of the study for their time who were obliged to look after palliative care patients, while spending time with patients.

\section{REFERENCES}

[1] Eun Y, Hong IW, Bruera E, Kang JH. Qualitative study on the perceptions of terminally ill cancer patients and their family members regarding end-of-life experiences focusing on palliative sedation. J Pain Symptom Manage 2017; 53(6):10101016.

[2] Rowland C, Hanratty B, Pilling M, van den Berg B, Grande G. The contributions of family care-givers at end of life: $A$ national post-bereavement census survey of cancer carers' hours of care and expenditures. Palliat Med 2017;31: 346-355.

[3] Rome RB, Luminais $\mathrm{HH}$, Bourgeois DA, Blais CM. The role of palliative care at the end of life. Ochsner J 2011;11: 348-352.

[4] Mitnick S, Leffler C, Hood VL. American college of physicians ethics professionalism and human rights committee. Family caregivers, patients and physicians: ethical guidance to optimize relationships. J Gen Intern Med 2010;25: 255-260

[5] Aoun S, Slatyer S, Deas K, Nekolaichuk C. Family caregiver participitation in palliative care research. J Pain Symptom Manage 2017; 53(5):851-861.

[6] Nielsen MK, Neergaard MA, Jensen AB, Vedsted $P$, Bro F, Guldin MB. Pre-loss grief in family caregivers during end-oflife cancer care: a nationwide population-based cohort study. Psychooncology 2017; 26(12):2048-2056.

[7] Rohrmoser A, Preisler M, Bar K, Letsch A, Goerling U. Early integration of palliative/supportive cancer care-healthcare professionals' perspectives on the support needs of cancer patients and their caregivers across the cancer treatment trajectory. Support Care Cancer 2017; 25(5):1621-1627.

[8] Dionne-Odom JN, Demark-Wahnefried W, Taylor RA, Rocque GB, Azuero A, Acemgil A, Martin MY, Astin M, Ejem D, Kvale $E$, Heaton K, Pisu M, Partridge EE, Bakitas MA. The self-care practices of family caregivers of persons with poor prognosis cancer: differences by varying levels of caregiver well-being and preparedness. Support Care Cancer 2017;25(8):24372444.

[9] Cagle JG, Bunting M, Kelemen A, Lee J, Terry D, Harris R. Psychosocial needs and interventions for heart failure patients and families receiving palliative care support: a systematic review. Heart Fail Rev 2017; 22(5):565-580.

[10] Tong HC, Kandala G, Haig AJ, Nelson VS, Yamakawa KS, Shin KY. Physical functioning in female caregivers of children with physical disabilities compared with female caregivers of children with a chronic medical condition. Arch Pediatr Adolesc Med 2002;156: 1138-1142.

[11] Hudak PL, Amadio PC, Bombardier C. Development of an upper extremity outcome measure: the DASH (disabilities of the arm, shoulder and hand). The Upper Extremity Collaborative Group (UECG). Am J Ind Med 1996;29: 602-608.

[12] N. B. WOMAC Osteoarthritis Index User Guide. Version V. Brisbane, Australia. 2002

[13] Vernon $H$, Mior S. The neck disability index: a study of reliability and validity. J Manipulative Physiol Ther 1991;14: 409-415.

[14] Craig CL, Marshall AL, Sjöström M, Bauman AE, Booth $M L$, Ainsworth BE, Pratt $M$, Ekelund $U$, Yngve A, Sallis JF, Oja P. International physical activity questionnaire: 12-country reliability and validity. Med Sci Sports Exerc 2003;35: 13811395.

[15] Ware JE, Jr., Sherbourne CD. The MOS 36-item short-form health survey (SF-36). I. Conceptual framework and item selection. Med Care.1992;30: 473-483. 
[16] Demiral Y, Ergor G, Unal B, Semin S, Akvardar Y, Kivırcık $B$, Alptekin K. Normative data and discriminative properties of short form 36 (SF-36) in Turkish urban population. BMC Public Health. 2006;6: 247.

[17] Beck JG, Stanley MA, Zebb BJ. Characteristics of generalized anxiety disorder in older adults: a descriptive study. Behav Res Ther 1996;34: 225-234.

[18] Pinto RA, Holanda MA, Medeiros MM, Mota RM, Pereira ED Assessment of the burden of caregiving for patients with chronic obstructive pulmonary disease. Respir Med 2007;101: 2402-2408.

[19] Bruns A, Hilario MO, Jennings F, Silva CA, Natour J. Quality of life and impact of the disease on primary caregivers of juvenile idiopathic arthritis patients. Joint Bone Spine 2008;75: 149154.

[20] Brehaut JC, Kohen DE, Raina P, Walter SD, Russell DJ, Swinton $\mathrm{M}, \mathrm{O}^{\prime}$ Donnell $\mathrm{M}$, Rosenbaum $\mathrm{P}$. The health of primary caregivers of children with cerebral palsy: how does it compare with that of other Canadian caregivers? Pediatrics 2004;114: e182-191.

[21] Raina $P, O^{\prime}$ Donnell $M$, Rosenbaum $P$, Brehaut J, Walter $S D$, Russell D, Swinton M, Zhu B, Wood E. The health and wellbeing of caregivers of children with cerebral palsy. Pediatrics 2005;115: e626-636.

[22] Tong HC, Haig AJ, Nelson VS, Yamakawa KS, Kandala G, Shin KY. Low back pain in adult female caregivers of children with physical disabilities. Arch Pediatr Adolesc Med 2003;157: 1128-1133.

[23] Alshubaili AF, Ohaeri JU, Awadalla AW, Mabrouk AA. Family caregiver quality of life in multiple sclerosis among Kuwaitis: a controlled study. BMC Health Serv Res 2008;8: 206.

[24] Alvarez-Ude F, Valdes C, Estebanez C, Rebollo P. Health-related quality of life of family caregivers of dialysis patients. J Nephrol 2004;17: 841-850.

How to cite this article: Pehlivan E, Balci A. Orthopedic Problems in Family Caregivers of Palliative Care Patients. Clin Exp Health Sci 2019; 9: 288-293. DOI: 10.33808/clinexphealthsci.532229 